Aletria, Belo Horizonte, v. 29, n. 3, p. 267-282, 2019

(c) (i)

\title{
A crítica (auto)biográfica brasileira contemporânea: configurações de um exercício
}

\section{The Brazilian (Auto)biographical Contemporary Criticism: Settings of an Exercise}

\author{
Jefferson Expedito Santos Neves \\ Universidade Federal da Bahia (UFBA), Salvador, Bahia / Brasil \\ jeffersonexpedito@outlook.com.br \\ Rachel Esteves Lima \\ Universidade Federal da Bahia (UFBA), Salvador, Bahia / Brasil \\ rachellima@uol.com.br
}

Resumo: O trabalho pretende analisar, brevemente, o modo como os críticos Eneida Maria de Souza (2007, 2011), Denilson Lopes (1999, 2002) e Diana Klinger (2014) têm se relacionado com a memória e o próprio sujeito num cenário contemporâneo atravessado pela apreensão imediata da presença e a espetacularização do eu, conforme Arfuch (2010). Além disso, busca-se refletir acerca das estratégias utilizadas na construção da tessitura de suas escritas avaliativas, entendidas não apenas como um saber, mas também como um fazer. Para tanto, apontam-se as contribuições do ensaio nos movimentos textuais efetuados pelos críticos, a partir das ideias desenvolvidas por Lopes (2009), Lima (2002) e Adorno (2003) a respeito do gênero. O crescente redirecionamento das posturas no campo revela ainda a vontade de se estabelecer um diálogo com audiências diversificadas, para além dos muros da universidade.

Palavras-chave: crítica biográfica; ensaio; procedimentos metodológicos.

Abstract: We aim to examine, briefly, how the critics Eneida Maria de Souza (2007, 2011), Denilson Lopes $(1999,2002)$ and Diana Klinger (2014) have been related to the memory and the subject itself in a contemporary scenario crossed by the immediate apprehension of the presence and the spectacularization of the "I", according to Arfuch 
(2010). In addition, we seek to think over on the strategies used in the construction of their written evaluation tenor, not only as a knowledge, but also as a way to make something. Therefore, we point out the test contributions in textual movements performed by critics, from the ideas developed by Lopes (2009), Lima (2002) and Adorno (2003) about the genre. The growing redirection of the postures in the field also shows the will to establish a dialog with diversified audiences, beyond the walls of the university.

Keywords: biographical criticism; test; methodological procedures.

Contemporaneamente, há um fascínio generalizado pela expressão mais imediata do vivido, do testemunhal, de modo que a avidez pelas vidas alheias, o sucessivo "falar de si", geraram uma proliferação de relatos memorialísticos. Com o avanço da midiatização das esferas políticas, sociais e culturais e o incessante desdobramento das tecnologias, a narrativa do "eu" teria se firmado, contribuindo para uma rede de intersubjetividades em que "o público" e o "privado" se tornariam difíceis de definir. A multiplicação de textos autorreferentes produziu um "espaço biográfico" composto por gêneros, como:

biografias [...], autobiografias, memórias, testemunhos, diários íntimos, [...], correspondências, cadernos de notas, de viagens, rascunhos, autoficções, romances, os inúmeros registros da entrevista [...], conversas, retratos, perfis [...] "talk show", "reality show" [...].

A apreensão do "corpo", da plenitude imediata da presença, peculiaridades do mundo de hoje, bem como a espetacularização do sujeito, obcecado pelo "verdadeiramente ocorrido", por contar a sua história, estariam articulados a um horizonte midiático em que predomina

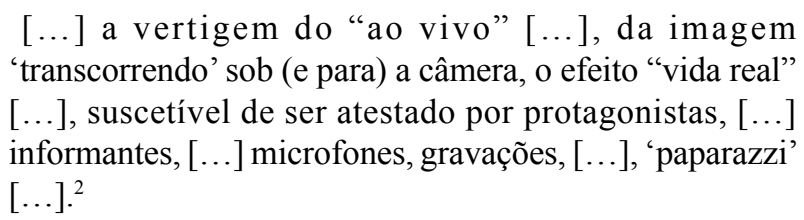

${ }^{1}$ ARFUCH. O espaço biográfico: dilemas da subjetividade contemporânea, p. 60.

${ }^{2}$ ARFUCH. O espaço biográfico: dilemas da subjetividade contemporânea, p. 75. 
Arfuch ressalta também os surtos dos blogs na internet e um indubitável "retorno do autor", em razão da ânsia existente pelos detalhes de sua vida, pelos "bastidores" da criação de seus livros.

Nessa linha de raciocínio, Diana Klinger (2006) nos diz que muitos romances atuais se voltam, de fato, sobre a experiência do autor: "Como produto da lógica da cultura de massas, cada vez mais o autor é percebido e atua como sujeito midiático." ${ }^{3}$. Todavia, a autora frisa que mesmo sendo a escrita do "eu" um sintoma do final do século, isso não significaria uma novidade, pois tal recurso já foi utilizado na história da literatura, sobretudo, latino-americana.

Assim, antes de examinarmos o modo como parte da crítica literária tem lidado com o sujeito e a memória nos últimos anos, gostaríamos de retomar a discussão sobre o "retorno do autor" defendido pelas intelectuais Leonor Arfuch (2010) e Diana Klinger (2006), em virtude da relevância do tema ao qual se dirigem em suas reflexões. Para tanto, remetemo-nos à "morte do autor" decretada por Roland Barthes, na década de 1960.

No célebre ensaio "A morte do autor" (2004), o crítico literário francês logo expôs, sem delongas, o rumo de suas ideias: "[...] a escrita é destruição de toda a voz, de toda a origem. A escrita é esse neutro, esse compósito, esse oblíquo [...], o preto-e-branco aonde vem perder-se toda a identidade, a começar precisamente pela do corpo que escreve." 4 O filósofo posiciona-se contra a onipotência e a onipresença do Autor nos manuais de história literária, nos estudos de literatura que tinham como fundamento seus gostos, manias, paixões; os próprios literatos se encontravam presos à prática de entrelaçar a pessoa $\mathrm{e} a \mathrm{obra}^{5}$. $\mathrm{O}$ teórico francês questiona, portanto, o reducionismo das investigações do texto literário, limitadas a considerá-lo como reflexo da vida do escritor. Tal perspectiva unilateral de leitura, cuja finalidade era descobrir sob um prisma teleológico a "verdade" do romance ou da poesia, foi denunciada, bem como o papel da crítica literária para firmar o "Império do Autor",

\footnotetext{
${ }^{3}$ KLINGER. Escritas de si, escritas do outro: autoficção e etnografia na narrativa latino-americana contemporânea, p. 36.

${ }^{4}$ BARTHES. A morte do autor, p. 57.

${ }^{5}$ BARTHES. A morte do autor, p. 58.
} 
proprietário da essência do texto, que seria, aliás, "um espaço de dimensões múltiplas", "um tecido de citações, oriundas dos mil focos da cultura."

Em contrapartida, de acordo com Arfuch (2010) e Klinger (2006), não é possível apagar completamente a figura do autor hoje, mas este retorna não como última instância do significado do texto, senão como provocação, num jogo entre referente e discurso ficcional, verossimilhança e inverossimilhança, como alguém que representa um papel em palestras, que posa em entrevistas, que se expõe ao público. Logo, numa sociedade singularizada por exibicionismos, os inúmeros registros que constituem o "espaço biográfico", mencionado acima, interagiriam entre si, ocasionando um impacto na (re)configuração da subjetividade contemporânea.

Por outro lado, a vontade atual de tudo preservar, conforme afirma o historiador Pierre Nora (1993), é entendida sob uma ótica pessimista, uma vez que haveria um processo de liquidação da memória, devido ao acúmulo documental excessivo gerado ao se reconstruir integralmente um passado sem lacunas, totalizador. Na realidade, esse desejo se mostra vão, pois nos apropriamos sempre de uma experiência intransmissível e inapreensível, daquilo que sabemos não mais nos pertencer:

[...] à medida em que desaparece a memória tradicional, nós nos sentimos obrigados a acumular religiosamente [...], testemunhos, documentos, imagens, discursos, sinais visíveis do que foi, como se esse dossiê cada vez mais prolífero devesse se tornar prova em não se sabe que tribunal da história. ${ }^{7}$

Instaurar-se-ia, segundo o historiador, uma memória de papel, registradora, que dublaria o vivido, porque "delega ao arquivo o cuidado de se lembrar por ela."» Tamanha materialização da memória, que para Nora estaria vinculada ao gesto, ao espaço, à imagem, aos saberes do corpo, enquanto elemento de uma coletividade, deixou de ser espontânea, social, coletiva e virou uma obrigação individual, um

\footnotetext{
${ }^{6}$ BARTHES. A morte do autor, p. 62.

${ }^{7}$ NORA. Entre memória e história: a problemática dos lugares, p. 15.

${ }^{8}$ NORA. Entre memória e história: a problemática dos lugares, p. 5.
} 
"dever", transformando-se em história, ou seja, "a reconstrução sempre problemática e incompleta do que não existe mais." "

Apesar de seus lamentos, Nora evidencia o desejo social em valorizar os rituais, as celebrações, os vestígios, os monumentos, referências tangíveis, isto é, a ambição de dar forma ao que seria o "imaterial". Essa passagem da memória para a história fez com que cada grupo redefinisse sua identidade pela revitalização da própria trajetória: "A psicologização integral da memória contemporânea levou a uma economia singularmente nova da identidade do eu, dos mecanismos da memória e da relação com o passado." ${ }^{10}$

Num contexto sublinhado pelo anseio em dar ao rosto um nome próprio, reproduzimos as inquietações de Denilson Lopes (2009) a respeito da adoção de novas posturas na esfera da crítica literária brasileira na atualidade:

Qual seria a resposta de nossa crítica a esta pulsão autobiográfica em tempos que o sexo rei há muito virou espetáculo de milhões, que a autobiografia de qualquer amante de celebridade se julga no direito de contar sua estória, que a internet é povoada por chats e diários públicos? Seria possível uma nova poética da expressão sem as ilusões românticas? ${ }^{11}$

Tais questionamentos nos serviram de mote para avaliarmos, como possibilidade de resposta, determinados exercícios analíticos realizados por críticos como Eneida Maria de Souza $(2007,2011)$ pelo próprio Denilson Lopes (1999, 2002) e por Diana Klinger (2014), por exemplo, devido à forma como se expõem e se conectam aos seus objetos de estudo, os recursos elaborados no ato da escrita, a fim de tornar o texto um "objeto-fetiche", entrelaçando argumento teórico, imaginação e história de vida, estratégia de sedução do leitor.

A princípio, asseguramos que, especialmente, a crítica biográfica engendrada por Eneida Maria de Souza ${ }^{12}$ é distinta da prática textual

\footnotetext{
${ }^{9}$ NORA. Entre memória e história: a problemática dos lugares, p. 9.

${ }^{10}$ NORA. Entre memória e história: a problemática dos lugares, p. 18.

${ }^{11}$ LOPES. Ensaio ou estar entre saberes, p. 3.

${ }^{12} \mathrm{O}$ trabalho crítico literário de Souza foi investigado na dissertação de mestrado intitulada A crítica em devir: uma análise da trajetória intelectual de Eneida Maria de Souza (2016), orientada pela Profa. Dra. Rachel Esteves Lima. Examinou-se um material vasto de ensaios
} 
que elucidava a obra a partir da vida do autor, método que obteve como um dos seus expoentes, o crítico francês Sainte-Beuve no século XIX. Sua técnica foi assimilada por muitos críticos de seu tempo e teve ecos no século XX. No entanto, para Souza, não se deve naturalizar os acontecimentos, pois: "[...] o elemento factual da vida/obra do escritor só adquire sentido se for transformado e filtrado pelo olhar do crítico, se passar por um processo de desrealização [...]." 13

O exercício da crítica biográfica proporcionaria ao "sujeito do conhecimento" uma liberdade criativa em razão de certa flexibilidade ficcional sobre o objeto analisado. A desestabilização do referente produziria a estetização da memória que não se encontra mais subordinada à prova de veracidade. Contudo, não se trata de converter o ficcional em real, mas de propor ambiguidades, deslizamentos entre esses espaços. ${ }^{14}$ Tamanha metodologia reforça a incapacidade do sujeito de se manter íntegro e onipotente, pois subjetividades são encenadas, o que, em certa medida, se coaduna com o pensamento de Stuart Hall $(2005)^{15}$, que salienta a falácia do homem unívoco e coerente.

$\mathrm{Na}$ sua atividade, Souza desloca o lugar da literatura como corpus exclusivo de pesquisa ao explorar tanto a produção ficcional quanto a documental dos escritores, valendo-se de correspondências, depoimentos, biografias, ensaios, entrevistas, confissões, dentre outros gêneros discursivos. A amplitude e a introdução de novos corpora no interior da teoria da literatura resultaram, sobretudo, das contribuições dos Estudos Culturais e de seu caráter interdisciplinar entre os campos do conhecimento ${ }^{16}$.

Em O século de Borges (1999), coletânea de ensaios lançada em comemoração ao centenário do escritor Jorge Luis Borges, Souza apresenta as peculiaridades do universo borgiano, o contextualiza e o recria, articulando simbolicamente dados biográficos e temas caros a

produzidos pela autora, através de uma perspectiva diacrônica, a fim de se observarem as transformações, os deslocamentos efetuados durante sua travessia nas esferas da crítica e da teoria da literatura; de modo que se constatou uma posição ambivalente no campo, ao se tentar conciliar teorias e enfoques metodológicos que deixam de ser predominantemente textuais para serem também históricos, sociais e culturais.

${ }^{13}$ SOUZA. Notas sobre crítica biográfica, p. 20.

${ }^{14}$ SOUZA. Notas sobre crítica biográfica, p. 22.

${ }^{15}$ HALL. A identidade cultural na pós-modernidade, p. 23

${ }^{16}$ CULLER. Teoria Literária: uma introdução, p. 33. 
sua poética, como a questão do "duplo". A crítica não se atém à imagem do autor associada apenas a Buenos Aires, a um sofrimento final no ocaso de sua existência, distanciando-se de interpretações sentimentais e subjetivas. Para Souza, Borges representaria a literatura do século XX marcada pelo repúdio do discurso positivista do século anterior: "Ainda que tenha nascido no apagar das luzes do século XIX, Borges imprime no século XX, o seu traço ficcional, tornando-o borgiano." 17

É interessante observar no ofício da ensaísta a apropriação de elementos característicos da escrita literária de Borges, como a mescla de teoria e ficção, simultaneamente. Entretanto, Souza não dilui fontes como faz o escritor ao embaralhar fronteiras, pois a crítica delineia os lugares aos quais se direciona, porém sempre os pondo em relação, num cruzamento entre instâncias discursivas, procedimento recorrente no seu gesto analítico.

A autora relata encontros reais entre Borges e outras personalidades e também promove encontros imaginários, por meio de um encadeamento que ocorre através de uma data ou de um ano específico. Expõe e metaforiza as idas e vindas de Borges a Genebra, debruça-se cuidadosamente sobre sua obra, mas, ao mesmo tempo, dela toma distância, como se para falar do outro precisasse necessariamente afastar-se.

Por meio de temas como o exílio, "voluntário", no caso de Borges e obrigatório em Gonçalves Dias, Souza aproxima os escritores afastados temporal e espacialmente. $\mathrm{O}$ autor argentino não nutriu $\mathrm{O}$ desejo de morrer no país de origem, ao contrário de Gonçalves Dias, vítima de um naufrágio antes de chegar a sua terra natal. As analogias são mediadas pela literatura, de modo que a crítica expande o diálogo entre Brasil e Argentina ao articular a ficção de Borges com a do mineiro Autran Dourado, bem como ao abordar o momento que se encontram em 1970, em São Paulo. Borges esteve no país para receber o "Prêmio Interamericano de Literatura Matarazzo Sobrinho".

Nesse contexto, a pesquisadora esboça outras associações como as que seguem abaixo:

Em 1954, o destino promove o encontro inusitado entre Borges e um outro brasileiro: Getúlio Vargas, que se suicida em 24 de agosto, no Palácio do Catete. Dois anos antes, a morte de Evita Perón já anunciava o fim da ditadura

${ }^{17}$ SOUZA. O Século de Borges, p. 20. 
argentina e a simultânea queda do autoritarismo mesclado ao populismo. No ano da morte de Vargas, registra-se ainda a perda definitiva da visão de Borges, que o transformará no rapsodo e no recitador de textos e de conferências ao redor do mundo, reforçando a imagem da realidade como simulacro e a concepção do discurso histórico como farsa e repetição teatral. $\mathrm{O}$ dia do nascimento do escritor, 24 de agosto, coincide com a data da morte do duplo político de Perón, coincidência histórica que une o destino das personagens, as quais se revelam ao mesmo tempo distanciadas e próximas. ${ }^{18}$

Dessa forma, crítica e criação não são termos antagonistas na atividade de Eneida Maria de Souza, discípula de Borges. Ao longo do livro, oscila entre imagem e conceito, representação e realidade ao conjugar teoria, imaginação e dados biográficos, postos em deslize, em trânsito, criando pontes entre o "real" e o ficcional. Nesse sentido, projeta dimensões simbólicas variadas, assumidas, por exemplo, pela cegueira ou pela "biblioteca" na vida do escritor:

Em Borges, o vínculo entre o discurso da cegueira e o da literatura permite a sua inserção na linhagem de escritores cegos, tais como Homero, Milton, Prescott e Joyce; na sua história familiar e na tradição dos diretores da Biblioteca Nacional, guardiães cegos do saber enciclopédico, como Groussac e Mármol. ${ }^{19}$

A simulação no jogo da escrita crítico-biográfica está associada ainda ao objetivo da intelectual de pôr em tensão tradições culturais diferentes e autores afastados no tempo, unidos por temas como a morte, a cegueira ou o exílio, como foi aqui demonstrado. Há um empenho em fundir gênero romanesco à história de vida sem atribuir maior peso ao registro do fato, intercalando argumento teórico e imaginação, de modo que a impossibilidade em delimitar um "eu" não deixaria de ser uma resposta ao desejo do leitor de encontrar o autor na página seguinte do livro, indo em sentido contrário ao ler e escrever no que consideramos como pós-modernidade.

${ }^{18}$ SOUZA. O Século de Borges, p. 16-17.

${ }^{19}$ SOUZA. O Século de Borges, p. 38-39. 
Para Linda Hutcheon (1991), a natureza do "pós-moderno" é híbrida, plural e contraditória, pautada em revisões críticas, reflexivas, porém nunca nostálgicas do passado: "Ele [o pós-modernismo] não sugere nenhuma busca para encontrar um sentido atemporal [...], mas sim uma reavaliação e um diálogo em relação ao passado à luz do presente.” ${ }^{20}$ Segundo Hutcheon, a metaficção historiográfica seria um gênero representativo da pós-modernidade ao transformar e reelaborar formas e conteúdos anteriores, subvertendo convenções a partir de dentro das mesmas, por meio de uma perspectiva ficcional-reflexiva e autorreflexiva. Os limites entre arte e vida são desafiados como na crítica de Souza, que parte da obra para construir sentidos e narrativas acerca de escritores e ambientes literários, em que cenas de escrita e de leitura são engendradas. Cabe pôr em relevo que, sem se deixar seduzir pela poeira dos arquivos ou pela tentação da observação microscópica, o olhar transversal de Souza amplia o horizonte da crítica biográfica.

No texto "Eu \& as galinhas-d'angola" (2006), tomado aqui como um dos muitos exemplos que poderiam ser citados a partir da obra de Santiago, o autor, para falar de si e explanar suas ideias, se utiliza de metáforas e símbolos literários, de modo que a impossibilidade em delimitar um "eu" é ratificada quando alega: "O desejo de personificar um corpo num rosto único, de dar ao rosto um nome próprio singular, não está em contradição com o estatuto do viver-em linguagem, do ler e escrever na pós-modernidade?"21

Souza, ao pôr em tensão tradições culturais diversas e autores afastados no tempo, unidos por temas como a morte, a cegueira ou o exílio, empenha-se em reler e teorizar seus percursos, fundindo gênero romanesco à história de vida sem atribuir maior peso aos acontecimentos, de modo que a impossibilidade em delimitar um "eu" não deixaria de ser uma resposta, ainda que artificial, ao desejo do leitor em encontrar o autor na página seguinte do livro.

Cabe-nos recordar que Stuart Hall (2005) ${ }^{22}$ nos alerta para o fato de que as sociedades modernas estariam passando por um processo de transformação que abalou as estruturas culturais, sociais e étnicas, que, num certo sentido, fundamentavam discursos centralizadores e ofereciam

\footnotetext{
${ }^{20}$ HUTCHEON. Poética do pós-modernismo: história, teoria, ficção, p. 31 .

${ }^{21}$ SANTIAGO. Eu \& as galinhas-d'angola, p. 4.

${ }^{22}$ HALL. A identidade cultural na pós-modernidade, p. 25.
} 
aos indivíduos quadros de referência estáveis. Numa cena permeada por desestabilizações, o sujeito, consequentemente, sofreria um duplo deslocamento, uma vez que seus lugares socioculturais e pessoais, antes concebidos como zonas fixas, estariam se desintegrando, de maneira que vislumbraríamos a emergência de um ser pós-moderno plural, mutável, descentrado, que assume diferentes identidades em momentos distintos.

Diante disso, formas textuais relativamente instáveis, fronteiriças, têm despontado na crítica brasileira, assim como a tentativa do pesquisador de se aproximar de seu objeto de estudo. Em Nós, os mortos: melancolia e neo-barroco (1999), Denilson Lopes efetua movimentos em torno do tema que se propõe estudar sem blocos temáticos ou capítulos, numa colagem de citações, imagens, divagações, conjugando crítica e criação.

A obra de Lopes possui como temática recorrente estudos sobre a homoafetividade, questões de gênero, do público LGBT, num momento em que as inquirições sobre as comunidades gays se iniciam nas universidades brasileiras e norte-americanas, por exemplo. As suas produções estão invariavelmente atreladas a experiências pessoais, anotações íntimas, projeções subjetivas encenadas a fim de agradar a esse leitor ávido pelos relatos de vida, pelo testemunho. Ao mesmo tempo, não deixa de ser um sintoma da identidade performativa do sujeito contemporâneo: "Tudo em mim faz dor, mesmo o próprio prazer. Um simples gesto, uma palavra me desmorona. [...]. Estes romances, estes filmes. Diário da dor. Morrendo. Nunca mais. Morto." ${ }_{23}$

Lopes radicaliza o uso da primeira pessoa na grande maioria de seus ensaios. O narrador não tem receio de forjar a própria máscara diante do leitor, de entregar-se e perder-se no próprio objeto, sem, no entanto, prejudicar a densidade das ideias explicitadas. O livro aqui investigado analisa filmes e romances, prezando pelo fragmento, passagens que podem ser lidas aleatoriamente sem que se perca muito o sentido da obra. Há ainda digressões, aforismos, interrupções, avaliações do crítico que se apresentam em estilhaços, num ritmo intenso, em que tudo é lançado na face do leitor para que se mova e adentre no texto, construa o próprio caminho, mergulhado que está no fluxo de palavras e imagens. O que nos interessa é a sua capacidade de efetuar inquirições sem hermetismos ou demasiadamente abstratas, conceituais, sua proposta de construir uma crítica com "afeto" e com o próprio "corpo".

${ }^{23}$ LOPES. Nós, os mortos: melancolia e neo-barroco, p. 86. 
No último ensaio de $O$ homem que amava rapazes (2002), o professor da Universidade Federal do Rio de Janeiro, refletiu a respeito do vínculo entre experiência e escrita, de modo que a primeira seria uma força para a criação, ainda que alegue temer recair em "confessionalismos narcísicos":

A experiência não é apreendida para ser repetida, simplesmente, passivamente transmitida, ela acontece para migrar, recriar, potencializar outras vivências, outras diferenças. Há uma constante negociação para que ela exista, não se isole. Aprender com a experiência é sobretudo fazer daquilo que não somos, mas poderíamos ser, parte integrante de nosso mundo. A experiência é mais vidente que evidente, criadora que reprodutora. ${ }^{24}$

Após tamanho projeto ser delineado, o sujeito da enunciação pinta-se através de um travestimento na escrita que se configura, em suma, como uma alternativa textual para lidar com as demandas do nosso tempo, estratégia de reinvenção de si usada na pós-modernidade. Ao analisar o filme Morte em Veneza, do cineasta italiano Luchino Visconti (1971), baseado na novela homônima de Thomas Mann, no final do ensaio, teatralmente, nos diz:

Volto o filme. Olho uma vez mais o rosto de Tadzio imobilizado no vídeo. Levanto da poltrona. Desejo tocá-lo. Não consigo evitar as lágrimas. Desligo a televisão. Tela escura. Sozinho em casa. O céu de Brasília é um oceano. Já não penso mais em Tadzio, nem em tantos outros rapazes, que não cessam de passar pela minha vida. As imagens vão se misturando. Os nomes se apagando. Durmo um pouco. Pensei que fosse pouco. Mas a noite já terminava. Não há ruídos na casa. Não há ninguém. Apenas o dia querendo nascer. ${ }^{25}$

A figuração do crítico como personagem do próprio texto é um recurso que pode ser evidenciado também em Literatura e ética: da forma para a força (2014), de Diana Klinger, obra que faz parte da coleção de ensaios Entrecríticas, série que reúne autores brasileiros e

\footnotetext{
${ }^{24}$ LOPES. O homem que amava rapazes, p. 187-188.

${ }^{25}$ LOPES. O homem que amava rapazes, p. 44-45.
} 
argentinos lançada pela editora Rocco e organizada por Paloma Vidal, visando estabelecer um diálogo entre crítica literária e outras artes. $\mathrm{O}$ livro, redigido em primeira pessoa, foi estruturado na forma de três cartas dirigidas à amiga de Klinger, docente da UFRJ, Luciana Di Leone, que inclusive participou da coleção com o livro Poesia e escolhas afetivas: edição e escrita na poesia contemporânea (2014).

Klinger examinou poemas, estudos, discussões em torno de filósofos como Theodor Adorno, Walter Benjamim, Spinoza, Michel Foucault, Jacques Derrida, Gilles Deleuze, Nietzsche e o escritor e crítico Maurice Blanchot. Mesmo negando o estatuto de crítica literária do que considera como "anotações de pensamentos suscitados por essas leituras" ${ }^{26}$, sua dicção não deixa de se configurar como outra maneira interessante de expressão no âmbito intelectual brasileiro, ao mesclar texto teórico, relatos confessionais, fotos, análises de obras de autores como Roberto Bolaño, Julio Cortázar e Tamara Kamenszain. Logo no início, o tom do ensaio se expressa:

Estas anotações partem de situações autobiográficas, que são o impulso que me arrasta a certas leituras, a certos autores, a certas perguntas. É o livro mais exposto que eu poderia escrever: resolvi me expor com toda a força, a fraqueza, a potência e a vulnerabilidade do meu próprio eu. ${ }^{27}$

Por outro lado, não há impressionismos na tarefa da autora, muito pelo contrário: os mecanismos que compõem os ensaios, em síntese, abarcam memórias e uma bagagem teórica compilada ao longo de sua carreira acadêmica. A ficcionalização de si, procedimento literário contemporâneo ${ }^{28}$, nos parece que foi, num certo sentido, transposta para o campo da crítica literária, como tática útil em meio a um horizonte de exibicionismos em todas as esferas da sociedade e da ânsia pela captura incessante da intimidade do "outro":

\footnotetext{
${ }^{26}$ KLINGER. Literatura e ética: da forma para a força, p. 14.

${ }^{27}$ KLINGER. Literatura e ética: da forma para a força, p. 7.

${ }^{28}$ Consoante Luciene Azevedo (2013), a “autoficção" seria uma estratégia representacional da literatura contemporânea, em que "as fronteiras entre o biográfico e o ficcional aparecem [...] mescladas no seu limite [...]." (p. 158). Assim, o hibridismo conscientemente engendrado pelos escritores bagunçaria o horizonte de expectativa do leitor.
} 
Na tela do computador, a minha imagem se reflete enquanto escrevo. Posso ver no reflexo, o rapaz que estuda na mesa vizinha: parece bonito e tem um cachecol. Adoro homens de cachecol. Faz muito frio 'aqui dentro', na sala de leitura do CCBB [...]. Me pergunto se ele percebe que eu o observo. De vez em quando, ele olha para mim, de lado. Disfarça. Eu também disfarço: volto ao livro, à página opaca, sem reflexos. É um volume de contos intitulado 'Deshoras', o último livro publicado por Cortázar, há 30 anos. Imagino Cortázar na frente da Olympia, fumando seu Gitanes, olhando para fora da janela da cidade cinzenta. [...]. É Paris. As janelas estão um pouco embaçadas e o pequeno apartamento cheira a cigarro. Posso imaginar, no silêncio do final da tarde, o barulho que fazem as teclas da Olympia ao digitar. ${ }^{29}$

A pesquisadora confere potência à literatura no decorrer do livro, delineado por meio de uma linguagem fluida que aproxima os leitores menos habituados aos textos acadêmicos. $\mathrm{O}$ fazer crítico tanto de Klinger quanto de Lopes atribui supremacia à ficção, única forma possível de resgatar a lembrança, contornar a memória, dar legitimidade ao sujeito:

Escrevo no fim da noite, Lu, já não tenho mais cigarros nem forças. No fim, só restam a literatura e os amigos. [...]. Não aprendemos nada, apenas a sobreviver. [...]. Eu passei os dias naquela biblioteca, esboçando esse livro para dizer apenas que eu queria e precisava recuperar uma força que há na literatura e que a burocratização da vida acadêmica e a banalização da narrativa contemporânea tinham me feito esquecer. ${ }^{30}$

Portanto, ao menos uma parcela da atividade da crítica literária abandonou aspirações extremamente objetivas e imparciais, traços que perduraram por bastante tempo nesse campo, a fim de encontrar modos de expressão singulares, em conformidade com aspectos caros ao cenário contemporâneo ou pós-moderno, em que pesquisa e vida se misturam, num empreendimento disposto a arriscar-se fora de terrenos ou critérios delimitadores. Reconhece-se, assim, o teor incompleto e plural de todo

\footnotetext{
${ }^{29}$ KLINGER. Literatura e ética: da forma para a força, p. 11.

${ }^{30}$ KLINGER. Literatura e ética: da forma para a força, p. 71.
} 
ato interpretativo, liberando-se o crítico para possibilidades criativas de contato com o "outro", a literatura, o artefato cultural.

Podemos mencionar, inclusive, outros críticos que exercem um diferencial na tessitura de sua escrita avaliativa, entendida não apenas como um saber, mas também como um fazer. São eles: Raúl Antelo (2006), (2007), (2005), Carlos Secchin (2003), (2014) José Castello (2007), (2017) Nelson de Oliveira (2008), (2010), Silviano Santiago (2004), (2006) e Roberto Corrêa dos Santos (2010), (2012), por exemplo. Os movimentos textuais que têm se efetivado nas análises dos críticos estudados e flexibilizado a maneira como conduzem suas produções, num gesto de sobrevivência ao presente, foram viabilizados pela ausência de estrutura fixa do gênero que frequentemente manipulam, isto é, o ensaio.

Rachel Lima (1995) nos fez um alerta ao atestar que o ensaio tem se apresentado nos dias atuais: "como um espetáculo, utilizandose para isso das diversas estratégias de elaboração textual, que muitas vezes levam o discurso crítico a confundir-se com a ficção." ${ }_{31}$ Essas afirmações nos auxiliam na compreensão dos métodos empregados por Klinger e Lopes, pois, ao menos no que diz respeito às produções aqui abordadas, estariam elas mais próximas do que denominamos de "crítica autobiográfica" ou "crítica escritural", em que o sujeito ocupa o primeiro plano da enunciação. Entretanto, suas posturas não são nada ingênuas, pois subjazem às suas análises, uma sustentação teórica bem fundamentada.

O filósofo Theodor Adorno (2003) afirmou que o ensaio não se relacionaria a parâmetros deterministas, posto que reconhece a multiplicidade de sentidos presente em um único objeto. Sem prévias delimitações, a peculiar falta de rigidez na sua definição "[...] não admite que seu âmbito de competência lhe seja prescrito." "32 A forma do ensaio seria, na realidade, efêmera, parcial, e, portanto, adversa a enquadramentos. Em virtude do seu caráter contingente, descontínuo e fragmentário, uma vez que a própria realidade é fragmentada, negligencia certezas indubitáveis, posto que se torna "verdadeiro pela marcha de seu pensamento, que o leva para além de si mesmo, e não pela obsessão em buscar seus fundamentos como se fossem tesouros enterrados." ${ }^{33}$ Esse

${ }^{31}$ LIMA. O ensaio na crítica literária contemporânea, p. 303.

${ }^{32}$ ADORNO. O ensaio como forma, p. 16.

${ }^{33}$ ADORNO, O ensaio como forma, p. 30. 
traço aberto, parcial, em suspensão, que possibilita experimentações, foi apontado por Rachel Lima (1995) e Denilson Lopes (2009), os quais destacaram o desenvolvimento crescente, no exercício ensaístico da crítica, de um entrelaçamento entre arte e teoria, leveza e reflexão teórica.

$\mathrm{O}$ discurso crítico atual, ao menos no que diz respeito ao nosso corpus e, até onde investigamos, tem oscilado entre imagem e conceito, representação e realidade, conjugando teoria, imaginação e dados biográficos postos em trânsito. $\mathrm{O}$ que nos interessa, portanto, é a capacidade da crítica em efetuar inquirições que não sejam herméticas ou demasiadamente abstratas, indo de encontro a um modus operandi que destoa de procedimentos normativos dos séculos XIX e XX, como $\mathrm{o}$ aparato humanista e estruturalista. $\mathrm{O}$ redirecionamento das posturas no campo da crítica literária revela ainda a vontade de se estabelecer um diálogo com audiências diversificadas, para além dos muros da universidade, uma vertente expressiva da crítica que marginaliza a ideia de conceber o gesto analítico como "espelho retrovisor", mas sim como abertura para um processo em curso.

\section{Referências}

ADORNO, Theodor. O ensaio como forma. In: . Notas de Literatura I. Tradução de Jorge de Almeida. São Paulo: Editora 34, 2003. p. 15-45.

ARFUCH, Leonor. O espaço biográfico: dilemas da subjetividade contemporânea. Tradução de Paloma Vidal. Rio de Janeiro: EDUERJ, 2010 .

BARTHES, Roland. O rumor da língua. Tradução de Mário Laranjeira. São Paulo: Martins Fontes, 2004.

CULLER, Jonathan. Teoria Literária: uma introdução. Tradução de Sandra Vasconcellos. São Paulo: Beca Produções Culturais, 1999.

HALL, Stuart. A identidade cultural na pós-modernidade. Tradução de Tomaz Tadeu da Silva e Guacira Lopes Louro. 10. ed. Rio de Janeiro: DP \& A, 2005.

HUTCHEON, Linda. Poética do pós-modernismo: história, teoria, ficção. Tradução de Ricardo Cruz. Rio de Janeiro: Imago, 1991. 
KLINGER, Diana. Escritas de si, escritas do outro: autoficção e etnografia na narrativa latino-americana contemporânea. 2006. Tese (Doutorado) - Faculdade de Letras Universidade Federal do Rio de Janeiro, Rio de Janeiro: UFRJ, 2006.

KLINGER, Diana. Literatura e ética: da forma para a força. Rio de Janeiro: Rocco, 2014.

LIMA, Rachel Esteves. O ensaio na crítica literária contemporânea. Aletria: Revista de Estudos de Literatura, Belo Horizonte, v. 3, p.3541, out. 1995. Doi: https://doi.org/10.17851/2317-2096.3.0.35-41. Disponível em: http://www.periodicos.letras.ufmg.br/index.php/aletria/ article/view/1112. Acesso em: 26 ago. 2019.

LOPES, Denilson. Ensaio ou estar entre saberes. [S.l.]:[S.n.] 2009. Manuscrito. Disponível em: https://www.academia.edu/4915923/ Ensaio_ou_estar_entre_saberes. Acesso em: 19 fev. 2014.

LOPES, Denílson. Nós, os mortos: melancolia e neo-barroco. Rio de Janeiro: Ed. Sette Letras, 1999.

LOPES, Denilson. O homem que amava rapazes e outros ensaios. Rio de Janeiro: Aeroplano, 2002.

NORA, Pierre. Entre memória e história: a problemática dos lugares. Tradução de Yara Aun Khoury. Projeto História: Revista do Programa de Estudos Pós-Graduados em História, São Paulo, n. 10, p. 7-28, dez.1993.

SANTIAGO, Silviano. Eu e as galinhas d'angola. In: OLINTO, Heidrun Krieger; SCHOLLHAMMER, Karl Erik. Literatura e memória. Rio de Janeiro: Edições Galo Branco, 2006. p. 21-31.

SOUZA, Eneida Maria de. Notas sobre crítica biográfica. In:

Crítica Cult. Belo Horizonte: Ed. UFMG, 2002.

SOUZA, Eneida Maria de. O Século de Borges. Belo Horizonte: Autêntica, 2009. 